\title{
Model-based optimization of G-CSF treatment during cytotoxic chemotherapy
}

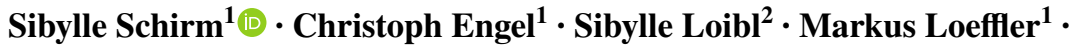 \\ Markus Scholz ${ }^{1}$ (1)
}

Received: 29 September 2017 / Accepted: 24 October 2017 / Published online: 4 November 2017

(C) The Author(s) 2017. This article is an open access publication

\begin{abstract}
Purpose Although G-CSF is widely used to prevent or ameliorate leukopenia during cytotoxic chemotherapies, its optimal use is still under debate and depends on many therapy parameters such as dosing and timing of cytotoxic drugs and G-CSF, G-CSF pharmaceuticals used and individual risk factors of patients.

Methods We integrate available biological knowledge and clinical data regarding cell kinetics of bone marrow granulopoiesis, the cytotoxic effects of chemotherapy and pharmacokinetics and pharmacodynamics of G-CSF applications (filgrastim or pegfilgrastim) into a comprehensive model. The model explains leukocyte time courses of more than 70 therapy scenarios comprising 10 different cytotoxic drugs.
\end{abstract}

Electronic supplementary material The online version of this article (https://doi.org/10.1007/s00432-017-2540-1) contains supplementary material, which is available to authorized users.

Markus Scholz

markus.scholz@imise.uni-leipzig.de

Sibylle Schirm

sibylle.schirm@imise.uni-leipzig.de

Christoph Engel

christoph.engel@imise.uni-leipzig.de

Sibylle Loibl

sibylle.loibl@gbg.de

Markus Loeffler

markus.loeffler@imise.uni-leipzig.de

1 Medical Faculty, Institute for Medical Informatics, Statistics and Epidemiology (IMISE), University of Leipzig, Haertelstraße 16-18, 04107 Leipzig, Germany

2 German Breast Group, c/o GBG Forschungs GmbH, Martin-Behaim-Straße 12, 63263 Neu-Isenburg, Germany
It is applied to develop optimized G-CSF schedules for a variety of clinical scenarios.

Results Clinical trial results showed validity of model predictions regarding alternative G-CSF schedules. We propose modifications of G-CSF treatment for the chemotherapies 'BEACOPP escalated' (Hodgkin's disease), 'ETC' (breast cancer), and risk-adapted schedules for 'CHOP-14' (aggressive non-Hodgkin's lymphoma in elderly patients).

Conclusions We conclude that we established a model of human granulopoiesis under chemotherapy which allows predictions of yet untested G-CSF schedules, comparisons between them, and optimization of filgrastim and pegfilgrastim treatment. As a general rule of thumb, G-CSF treatment should not be started too early and patients could profit from filgrastim treatment continued until the end of the chemotherapy cycle.

Keywords Cytotoxic drugs · Filgrastim - Pegfilgrastim · Leukopenia $\cdot$ Neutropenia $\cdot$ Risk-adapted treatment

\section{Background}

The haematopoietic growth factor G-CSF is routinely used in cancer therapy to prevent or ameliorate leukopenic conditions. Its effectiveness has been shown in several studies (Kosaka et al. 2015; Lee et al. 2013; Vogel et al. 2005; Altwairgi et al. 2013; Dale 2002, 2003; Kuderer et al. 2007; Crawford et al. 1991; Bohlius et al. 2008; Sung et al. 2007; Cooper et al. 2011; Mhaskar et al. 2014; Clark et al. 2003, 2005). Although G-CSF is expensive, its application often results in an overall cost-reduction due to the reduced number of severe events (Zagonel et al. 1994; Wang et al. 2016).

With the introduction of G-CSF support, more intense chemotherapies became feasible in order to improve 
outcome of patients (Trumper et al. 2008; Untch et al. 2011a, b; Pettengell et al. 1992; Pfreundschuh et al. 2004a, b, 2008; Diehl et al. 2003; Sieber et al. 2003; Blayney et al. 2003, 2005). A number of G-CSF pharmaceuticals are in use differing in both, pharmacokinetic and pharmacodynamic properties (Kuwabara et al. 1994, 1996a, b; Yang et al. 2004; Zamboni 2003; Molineux 2002; Houston et al. 1999). Various generics are available or under development.

Several in vivo modes of action of G-CSF are known, namely increased proliferation, accelerated maturation and improved release of mature bone marrow granulopoietic cells (Lord et al. 1989; Schmitz et al. 1993). In combination with the relatively short half-life of blood granulocytes and the bone-marrow suppressive effects of cytotoxic chemotherapy, application of G-CSF results in complex dynamics of blood granulocytes which cannot easily be predicted. As a consequence, optimal G-CSF support for a given chemotherapy and patient population is a non-trivial task. It depends on a large number of variable therapy parameters such as the type of cytotoxic drugs, granulotoxic risk factors of patients, type of G-CSF derivative applied and its dosing and timing (Bennett et al. 2013).

In clinical trials, it is practically impossible to control for each of these factors. Therefore, only limited attempts were made to compare the efficacy of different G-CSF schedules in the context of clinical trials (Danova et al. 2009; Holmes et al. 2002; Loibl et al. 2011; Lyman et al. 2009; Vose et al. 2003; Zwick et al. 2011; Faber et al. 2006; Crawford et al. 1997; Leonard et al. 2015). However, available clinical trials showed that considerable improvements can be expected by optimized G-CSF schedules. Since such trials are both, cost and time-intensive, there is relevant need to predict the outcome of alternative G-CSF schedules prior to clinical application. On the basis of large clinical and experimental data sets, we developed a comprehensive biomathematical model of human granulopoiesis including detailed information on injection, pharmacokinetics and pharmacodynamics of both, chemotherapeutic drugs and three G-CSF derivatives namely filgrastim, pegfilgrastim and the experimental drug MaxyG34 (Scholz et al. 2005, 2009a, 2009b, 2012; Chua et al. 2014; Engel et al. 2004; Schirm et al. 2013, 2014b). The model was validated in several settings and is now ready to make clinically relevant predictions regarding G-CSF schedules optimized for given chemotherapeutic regimens.

In this paper, we present our approach for developing optimized dosing and timing schedules of G-CSF for a variety of applications, i.e. for different chemotherapy schedules, risk groups of patients and usage of filgrastim or pegfilgrastim. Different measures of treatment outcome are considered. We also show examples of model predictions validated in the context of clinical trials.

\section{Methods}

\section{Model of human granulopoiesis}

We first introduce our biomathematical model of human granulopoiesis under chemotherapy and G-CSF support which is used to optimize G-CSF treatment during cytotoxic chemotherapy later. The model consists of a set of coupled differential equations describing time dependence of major bone marrow cell stages, circulating cells, cytokines at various sites, corresponding stimulation of bone marrow and toxic effects of chemotherapy. Treatments with G-CSF (filgrastim, pegfilgrastim) and chemotherapy (10 different chemotherapies, 33 different schedules for treatments for a variety of cancers) are modelled (Schirm et al. 2014b). Without any therapeutic intervention, a stable steady-state of all cell and cytokine compartments is achieved. The general structure of the model is shown in Fig. 1.

Equations can be attributed to three major mechanisms namely cell kinetics of bone marrow granulopoiesis, pharmacokinetics and pharmacodynamics of endogenous G-CSF and G-CSF pharmaceuticals (filgrastim, pegfilgrastim) and chemotherapy action. We briefly describe
Fig. 1 Schematic representation of human granulopoiesis model under chemotherapy and G-CSF treatment. Boxes represent major cell- or cytokine compartments of the model. We modelled two G-CSF derivatives, filgrastim and pegfilgrastim. Arrows represent cell/ cytokine fluxes and interactions

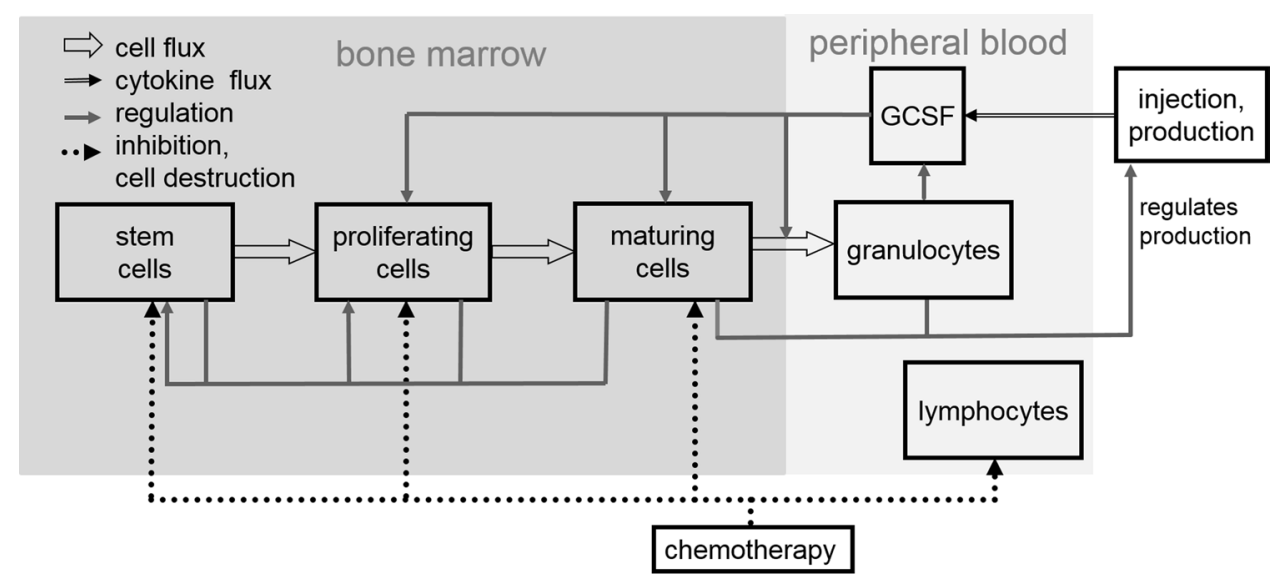


these major parts of the model and corresponding biological assumptions in the following.

The cell kinetic granulopoiesis model is explained in detail in Scholz et al. (2012). Here, we briefly sketch the main assumptions:

1. Granulopoietic cells originate from a pluripotent stem cell compartment. Cell division can create new stem cells or cells committed to granulopoietic lineage. All other haematopoietic lineages are neglected.

2. Subsequent proliferation and maturation of granulopoietic cells are described by transitions of cells from the stem cell compartment to the proliferating compartments of progenitor cells, proliferating precursors (PGB), and finally, maturing precursor cells which are unable to proliferate (MGB). For the latter, a postmitotic amplification is assumed which describes a loss of mature granulocytes in bone marrow due to apoptosis (Mackey et al. 2003). Finally, granulocytes are released to circulation (GRA). The system is regulated by several feed-back loops of which G-CSF is the strongest mediator.

3. The changes of the compartment sizes $\frac{\mathrm{d} C(t)}{\mathrm{d} t}$ in compartments $X$ are determined by balance equations of cell influx rate $C_{X}^{\text {in }}(t)$ from the preceding compartment, cell amplification $A(t)$ (if applicable), cell efflux dependent on the transition time $T(t)$, and loss rate $\Psi_{\text {total }}^{X}(t)$ caused by cytotoxic chemotherapy and named toxicity function in the following (Schirm et al. 2014b):

$\frac{\mathrm{d} C_{X}(t)}{\mathrm{d} t}=C_{X}^{\mathrm{in}}(t) \times A(t)-\frac{C_{X}(t)}{T(t)}-\Psi_{\text {total }}^{X}(t) C_{X}(t)$.

Increased G-CSF serum concentration results in higher amplification rate and longer transition time in the compartment $\mathrm{PGB}$, and reduced transition time and apoptosis rate in MGB.

\section{Pharmacokinetic model of G-CSF applications}

The most frequently used derivatives filgrastim and pegfilgrastim differ substantially in their pharmacokinetic properties. This is addressed by a general pharmacokinetic model of G-CSF injections developed for humans recently (Scholz et al. 2012):

1. Three compartments are modelled: G-CSF is injected into the subcutaneous compartment. In the central compartment, G-CSF is haematologically active. The peripheral compartment represents reversible binding of G-CSF (Scholz et al. 2005, 2012).
2. The influx of G-CSF from the subcutaneous compartment into the central compartment is delayed (Kota et al. 2007). This is modelled by splitting the subcutaneous compartment into two subcompartments.

3. Reversible bindings of G-CSF are modelled by transitions between central and peripheral compartment using first-order kinetics (Kuwabara et al. 1996b).

4. Endogenous production of G-CSF is regulated by the demand of mature granulocytes (Scholz et al. 2005).

5. Bioavailability of G-CSF is assumed to be dose-dependent. Thus, a part of the applied G-CSF is removed from the injection compartment by a Michaelis-Menten kinetic.

6. From the central compartment, G-CSF is irreversibly removed by two processes: a first-order kinetic describing the unspecific renal elimination (Kuwabara et al. 1996b) and a Michaelis-Menten kinetic describing the specific elimination by circulating granulocytes.

7. Differences in G-CSF derivatives filgrastim and pegfilgrastim are modelled by different settings of pharmacokinetic and pharmacodynamics parameters, i.e. parameters of the G-CSF-mediated regulatory feed loops (Harris and Chess 2003; Sarkar et al. 2003; Veronese and Mero 2008; Scholz et al. 2009b). Parameter values for filgrastim and endogenous G-CSF are the same.

\section{Chemotherapy model}

The impact of cytotoxic chemotherapy on haematopoiesis is modelled by drug, drug-dose and cell-stage specific toxicity functions in the following way (Schirm et al. 2014b):

1. A set of concatenated first-order transitions is used to model a delayed maximum of cell damage after the injection of chemotherapeutic drugs (Schirm et al. 2013).

2. When chemotherapeutic drugs were applied for the first time, we assume a somewhat higher toxicity than for further injections.

3. If multiple drugs are applied simultaneously, we add the corresponding toxicity functions to calculate the overall toxic effect.

4. Depletion of lymphocytes (LY) is phenomenologically modelled by an additional toxicity equation with two parameters.

5. The chemotherapy effect is assumed to be reversible. All cell-kinetic parameters remain unchanged.

6. Often, prednisone is applied to avoid tumour lysis syndrome. Prednisone is assumed to cause a prolonged half-life of granulocytes, and therefore, it temporarily increases granulocyte counts. 


\section{Data and model calibration}

The model was parametrized on the basis of clinical data of 10 different chemotherapies. These chemotherapies are used to treat patients with NHL (non-Hodgkin's disease), HD (Hodgkin's lymphoma), BRCA (breast cancer), NSCLC (non-small cell lung cancer), and DLBCL (diffuse large B cell lymphoma). An overview is presented in Table S1 in Additional file 1. Data were retrieved from published figures using the software tool "YCASD" (Gross et al. 2014) or directly from the clinical trial databases of cooperating clinical study groups. Model equations contain parameters for which often no direct biological data are available. This especially applies for parameters quantifying chemotherapy toxicity on bone marrow. These parameters were determined by fitting the model to the above-mentioned data sets as described elsewhere (Rechenberg 1973, 1994). Model parameters were validated on the basis of data sets not used for parameter fitting (Schirm et al. 2014b; Scholz et al. 2012).

\section{Application to risk groups}

Several risk factors associated with the degree of leukopenia under chemotherapy have been identified and validated in different settings. This comprises for example pre-therapeutic risk factors such as age, sex, WHO performance status as well as intra-therapeutic risk factors such as toxic response in the first therapy cycle. A risk model accounting for these factors was proposed by Ziepert et al. (2008) for CHOP chemotherapy. The risk model is implemented in a web-based tool (see http://www.toxcalculator.com). We used the tertiles of the risk score to divide our study population into low, medium and high-risk group and propose different G-CSF schedules for them in the following.

In order to apply our model to different risk groups, we assume that parameters regarding pharmacokinetics and pharmacodynamics of G-CSF as well as cell-kinetic parameters are constant among risk groups, but the parameters regarding chemotherapy toxicity might differ. This is motivated by observed heterogeneities regarding metabolism of cytotoxic drugs (Bruno et al. 1997; Kloft et al. 2006; Bennett et al. 1987; Sulkes and Collins 1987; Iyer and Ratain 1999; Rushing et al. 1994).

Applying this paradigm, we can derive risk-specific toxicity parameters of patients by fitting the predictions of the model to available data of the subgroups (Table S2 in Additional file 1).

\section{Model simulations of new chemotherapy schedules}

A key feature of the model is that new, yet untested schedules of both, chemotherapy and G-CSF treatment can be simulated. This requires that toxicity parameters of the chemotherapy are available for the population of interest, i.e. data of patients under at least one G-CSF schedule (or no G-CSF) of the chemotherapy of interest are required allowing to estimate the toxicity parameters thereon. Then, alternative timing of chemotherapy or G-CSF, alternative derivatives and dosing of G-CSF can be simulated by the model. An overview of already available toxicity parameters is listed in an earlier publication of our group (Schirm et al. 2014b).

\section{Optimization of therapy schedules}

To compare the performance of alternative G-CSF schedules for a given chemotherapy schedule of a given population of patients, we calculate a number of quantities mirroring the overall leukotoxicity: The area over the curve of white blood cells (WBCAOC) measures the area between simulated cell counts and the value of 4000 leukocytes/ $\mu \mathrm{L}$. There is some evidence that the risk of infectious complications in patients depends on the depth and the duration of leukopenia (Crawford et al. 2004; Li et al. 2016). We separately consider the duration of leukopenia (DoL) referring to the cumulative time of leukopenia and the minimal leukocyte count (MLC) referring to the minimal cell count throughout all chemotherapy cycles as alternative endpoints of G-CSF optimization (Fig. 2).

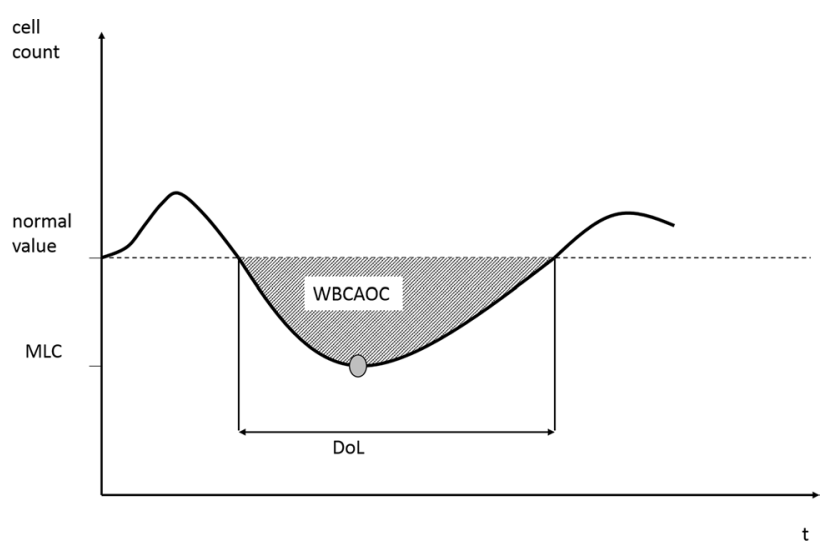

Fig. 2 Illustration of toxicity outcomes. We consider the area over the curve (WBCAOC), minimal cell count (MLC) and duration of low cell counts (DoL) as measures of severity of leukopenia. We treat 4.000 leukocytes/ $\mu \mathrm{L}$ as normal value for this purpose 


\section{Technical implementation}

The model equations were programmed and solved on a standard personal computer using the numeric computation software Matlab 7.5.0.342 and the integrated Simulink toolbox v7.0 (The MathWorks, Natick, MA). Model simulations were performed by numerical integration of the ODE system using the variable step solver from Adams and Bashford (ode113).

\section{Results}

\section{Validated model predictions}

In the past, we showed that our model can successfully predict the granulotoxic outcome of CHOP chemotherapy with G-CSF support. Some of these predictions were already tested in clinical trials resulting in improved filgrastim and pegfilgrastim schedules for CHOP chemotherapy. We present these successful predictions in brief. For CHOP-14 therapy in elderly patients we predicted that a reduced filgrastim schedule with applications at days (d) 6-12 of each cycle is also feasible compared to the standard $\mathrm{d} 4-13$ protocol. This was confirmed by retrospective analyses of the RICOVER trial in which both schedules were applied. We present the comparison of model and data for these scenarios in Fig. 3a, b. Interestingly, a recent simulation of Craig et al. (2015) also predicted that later start of filgrastim treatment could be advantageous for general 14 day schedules and that fewer injections are required in this case.

We also predicted that later applications of pegfilgrastim are advantageous compared to early applications in CHOP14 regimen of elderly NHL patients. This was confirmed in the pegfilgrastim trial comparing pegfilgrastim applied at $\mathrm{d} 2$ with $\mathrm{d} 4$ which resulted in a clear advantage of the latter with respect to leukocyte nadir, days with leukocytes $<2 \times 10^{3} /$ $\mathrm{mm}^{3}$, grade 3 and 4 leukocytopenias, grade 4-only leukocytopenias, grade 3 and 4 infections, deaths during leukocytopenia and interventional antibiotics (Zwick et al. 2011). It turned out that our predictions were not only qualitatively correct, but also in good quantitative agreement with the observed clinical data (Fig. 3c, d).

\section{Optimization of chemotherapy schedules without considering risk factors}

We now use our model to make predictions regarding optimal filgrastim schedules of a number of established and novel chemotherapy schedules. An overview of all optimized G-CSF schedules and corresponding WBCAOC values is presented in Table 1. Results for the other endpoints, DoL and MLC, can be found in Table S3 in Additional file 1.
BEACOPP escalated

Eight cycles of BEACOPP escalated is the German standard chemotherapy to treat intermediate and advanced stages of Hodgkin's disease in younger patients ( $<60$ years). According to study protocols, it is recommended to apply filgrastim at $\mathrm{d} 8-15$ at each cycle. Figure 4 shows the predicted median leukocyte time course of this schedule. We now varied both, starting day of G-CSF treatment and number of injections in order to predict WBCAOC of these alternative schedules (Fig. 5a, b). It revealed that leukopenia prophylaxis could be improved by starting earlier $(\sim \mathrm{d} 6-7)$ and providing a higher number of injections ( until the end of each cycle). We also considered substituting filgrastim by pegfilgrastim. We predict that in this case, pegfilgrastim should be applied at d6-7 to achieve optimal leukopenia prophylaxis.

\section{ETC}

The ETC regimen is used as adjuvant chemotherapy of breast cancer patients in the German Breast Group (Moebus et al. 2010). It consists of three consecutive cycles of epirubicin (E), paclitaxel (T), and finally, cyclophosphamide (C). Filgrastim was recommended to be applied at $\mathrm{d} 3-10$ of each cycle (Fig. 4). We predict that leukopenia prophylaxis can be clearly improved if G-CSF is applied at d6-13 (Fig. 5c, $\mathrm{d}$, Table 1, Table S3). If pegfilgrastim is used instead of filgrastim, it should be applied at d6 of each cycle (Fig. S1).

However, since haematotoxic risk differs considerably between the chemotherapeutic drugs (lowest for T, highest for C), it appears to be worthwhile to modify G-CSF schedules according to the drug currently applied. We implemented a stepwise optimization for this sequential chemotherapy taking the different cytotoxicities of the drugs into account: in cycles 1-3, G-CSF should be applied from d6-10. In cycles 4-9, optimal G-CSF therapy starts on d7 with 8 injections (Fig. S1 in Additional file 1). The optimal WBCAOC is 0.57 , while that of the current standard therapy is 14.9. The optimization assuming the same G-CSF schedule in each cycle (d7-14) yields 0.70 . Thus, the improvement by cycle-specific G-CSF schedules is only moderate compared to the optimal unique G-CSF schedule, which probably does not outweigh the higher organizational effort.

\section{CHOP-12}

Densification of CHOP chemotherapy from cycle duration 21 to cycle duration 14 resulted in improved outcomes of elderly NHL patients (Pfreundschuh et al. 2004a). This densification was only possible by intense leukopenia prophylaxis with either filgrastim or pegfilgrastim. By model simulation, we analysed whether a further time intensification 
a $\mathrm{CHOP} 14$, age $>60$, Fil. day $4-13$
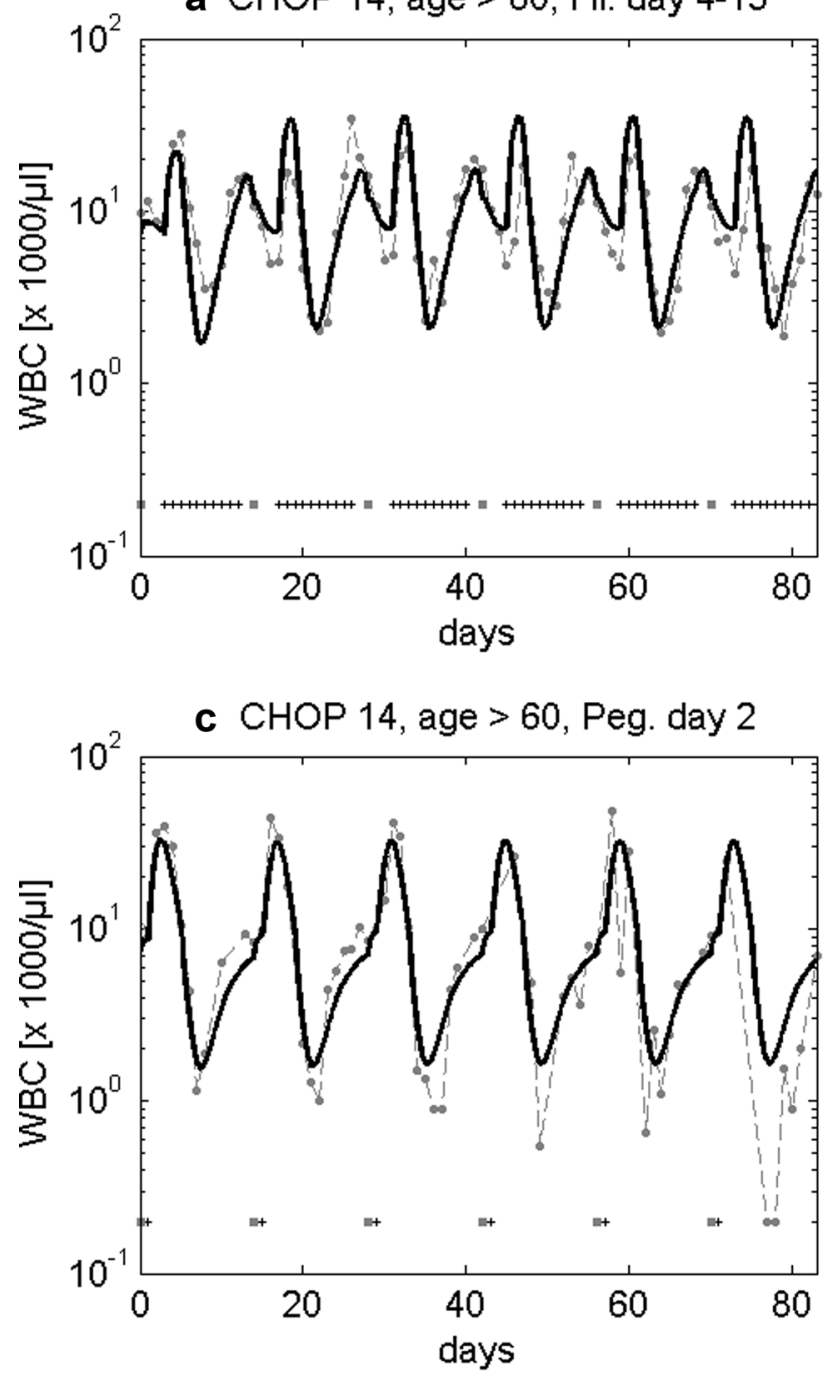

Fig. 3 Validation of model predictions. We compare model and data for six cycles of CHOP-14 for elderly patients either treated with filgrastim at cycle days 4-13 (a) or 6-12 (b). Dots represent patient medians, squares correspond to chemotherapy administrations, "+" correspond to days with G-CSF injections. Model predictions fit well to data of the RICOVER-60 trial and the NHL-B trial and show that the reduced G-CSF schedule is feasible (Schirm et al. 2014b; Zeynal-
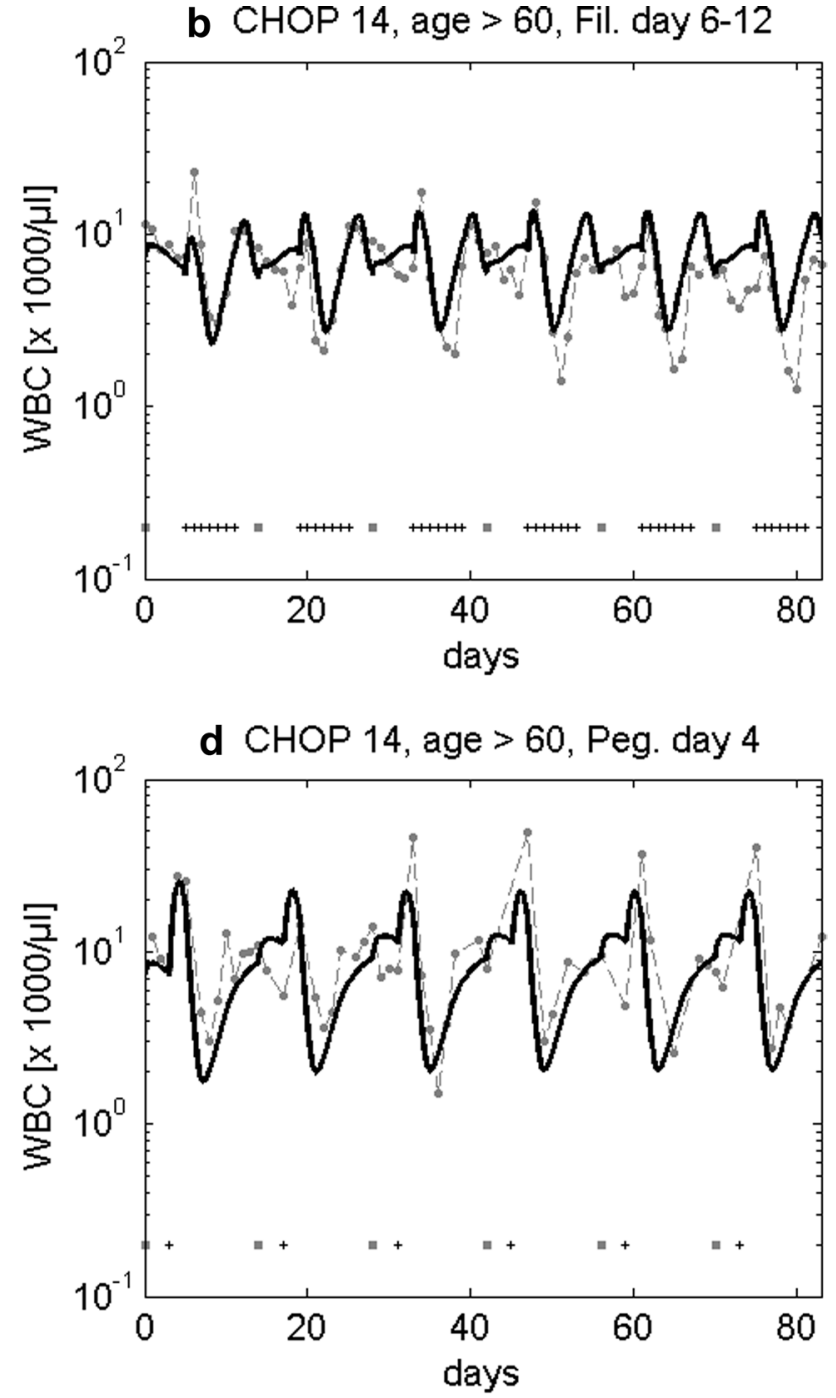

ova et al. 2013; Pfreundschuh et al. 2004a, 2008). We further predicted that later pegfilgrastim application is advantageous for CHOP14 chemotherapy of elderly NHL patients. This was compared in a randomized trial of pegfilgrastim day 2 (c) vs. day 4 (d) (Zwick et al. 2011). Again, a good agreement of model and data was observed (Schirm et al. 2014b)

\section{Optimization of G-CSF schedules considering individual risk factors}

G-CSF schedules proposed for the previous chemotherapies were optimized for medians of patients, i.e. patient's heterogeneity in toxic response was ignored so far. Here, we provide predictions for risk-adapted therapies using a recently proposed statistical model of leukopenia risk of elderly 
Table 1 Predicted WBCAOC values of different simulated G-CSF schedules, chemotherapies and risk groups

\begin{tabular}{|c|c|c|c|c|c|c|c|c|}
\hline Therapy & Risk group & $\begin{array}{l}\text { Optimal } \\
\text { start of Fil }\end{array}$ & $\begin{array}{l}\text { Optimal } \\
\text { \#Injection Fil }\end{array}$ & $\begin{array}{l}\text { Optimal out- } \\
\text { come value Fil }\end{array}$ & $\begin{array}{l}\text { Optimal } \\
\text { start of Peg }\end{array}$ & $\begin{array}{l}\text { Optimal out- } \\
\text { come value Peg }\end{array}$ & $\begin{array}{l}\text { Currently used } \\
\text { schedules }\end{array}$ & $\begin{array}{l}\text { Current } \\
\text { outcome } \\
\text { value }\end{array}$ \\
\hline \multirow[t]{12}{*}{ CHOP-14 elderly } & \multirow[t]{4}{*}{ High } & \multirow[t]{4}{*}{7} & \multirow[t]{4}{*}{8} & \multirow[t]{4}{*}{50.51} & \multirow[t]{4}{*}{7} & \multirow[t]{4}{*}{57.16} & Fil d4-13 & 72.58 \\
\hline & & & & & & & Fil d6-12 & 77.92 \\
\hline & & & & & & & Peg d2 & 112.45 \\
\hline & & & & & & & Peg d4 & 91.10 \\
\hline & \multirow[t]{4}{*}{ Medium } & \multirow[t]{4}{*}{9} & \multirow[t]{4}{*}{6} & \multirow[t]{4}{*}{2.16} & \multirow[t]{4}{*}{7} & \multirow[t]{4}{*}{2.81} & Fil d4-13 & 10.47 \\
\hline & & & & & & & Fil d6-12 & 7.55 \\
\hline & & & & & & & Peg d2 & 38.82 \\
\hline & & & & & & & Peg d4 & 22.14 \\
\hline & \multirow[t]{4}{*}{ Low } & \multirow[t]{4}{*}{8} & \multirow[t]{4}{*}{4} & \multirow[t]{4}{*}{0.00} & \multirow[t]{4}{*}{7} & \multirow[t]{4}{*}{0.00} & Fil d4-13 & 0.00 \\
\hline & & & & & & & Fil d6-12 & 0.00 \\
\hline & & & & & & & Peg d2 & 21.06 \\
\hline & & & & & & & Peg d4 & 6.94 \\
\hline BEACOPP esc & All & 7 & 15 & 62.07 & 7 & 52.98 & Fil d8-15 & 145.16 \\
\hline ETC & All & 7 & 8 & 0.70 & 6 & 5.34 & Fil d3-10 & 14.86 \\
\hline CHOP-12 elderly & All & 7 & 6 & 19.12 & 6 & 20.50 & - & - \\
\hline
\end{tabular}

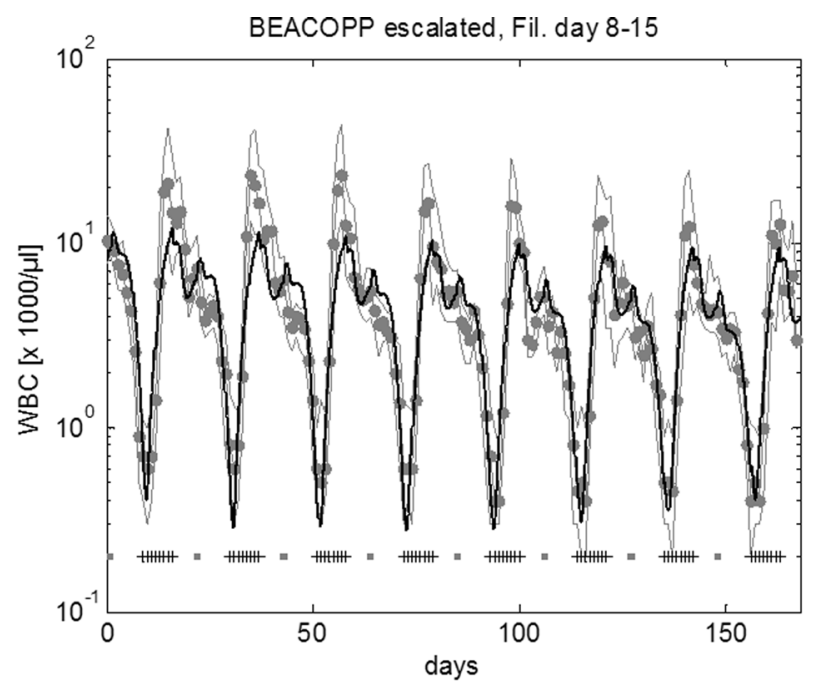

Fig. 4 Agreement of model and data for BEACOPP escalated and for ETC. We consider eight cycles of BEACOPP escalated chemotherapy of Hodgkin's lymphoma with filgrastim at cycle days 8-15 (left), and nine cycles of ETC adjuvant breast cancer chemotherapy with

patients under CHOP treatment. Patients were divided into three risk groups according to tertiles of the risk score.

Assuming that interindividual heterogeneity in toxic response can be traced back to differences in chemotherapy toxicity parameters rather than cell-kinetic parameters, we estimated these parameters for the three risk groups considered. Resulting agreement of model and data can be found in Fig. 6.

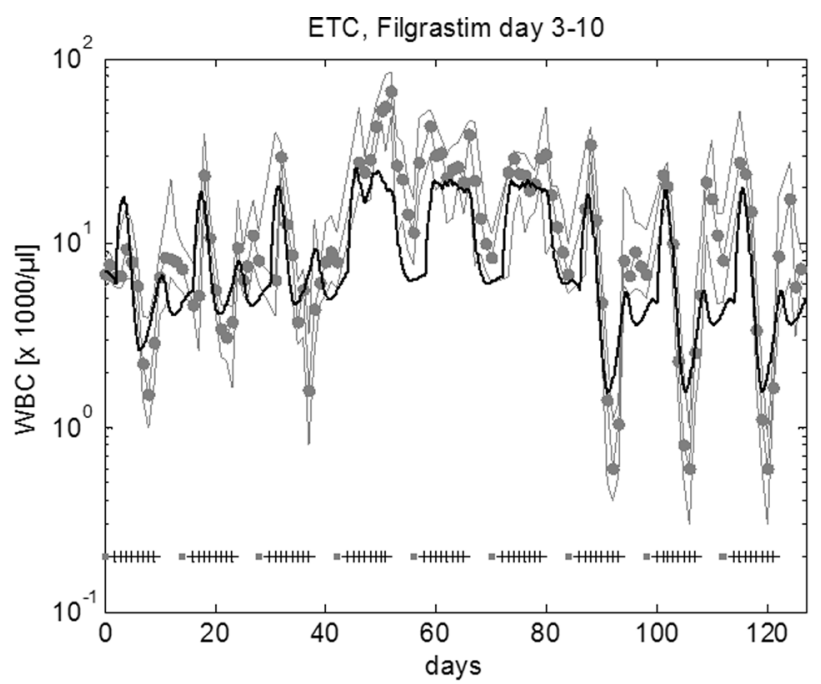

filgrastim at cycle days 3-10 (right). Dots represent patient medians, grey lines represent interquartile range of patient data, squares correspond to chemotherapy administrations, "+" corresponds to days with G-CSF injections

Estimated toxicity parameters can be used to make riskspecific predictions regarding specific optimal G-CSF schedules. We conclude that for the highest risk group, filgrastim treatment should be started around d6-8 after start of therapy cycle with at least eight injections (Fig. 7a, b). For the medium- and low-risk groups, timing is less important and 6, respectively, 4 injections result in sufficient recovery (Fig. 7c-f). 

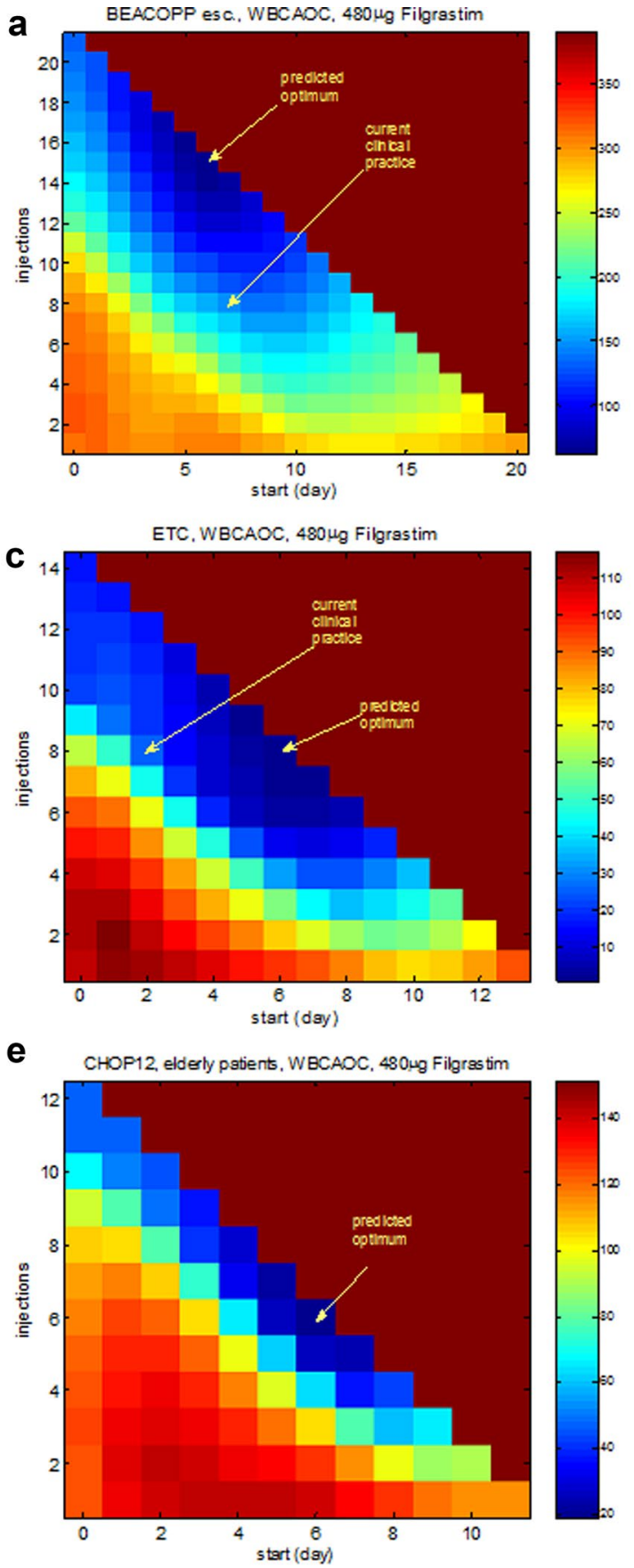

Fig. 5 Optimized G-CSF schedules for a variety of chemotherapies. a Optimization of eight cycles of BEACOPP escalated with filgrastim. b We consider eight cycles of BEACOPP escalated with filgrastim at cycle days 8-15 ("current clinical practice") and filgrastim at cycle days 7-21 ("predicted optimum"). c, d We consider nine cycles of ETC with filgrastim. Current clinical practice: filgrastim at cycle days 3-10. Optimization with the same G-CSF schedule in all

Pegfilgrastim should be injected around d6-7 after chemotherapy in the high-risk and medium-risk group. For the low-risk group, timing is not important (Fig. S2b, d, f in Additional file 1). Regarding pegfilgrastim dosing, we
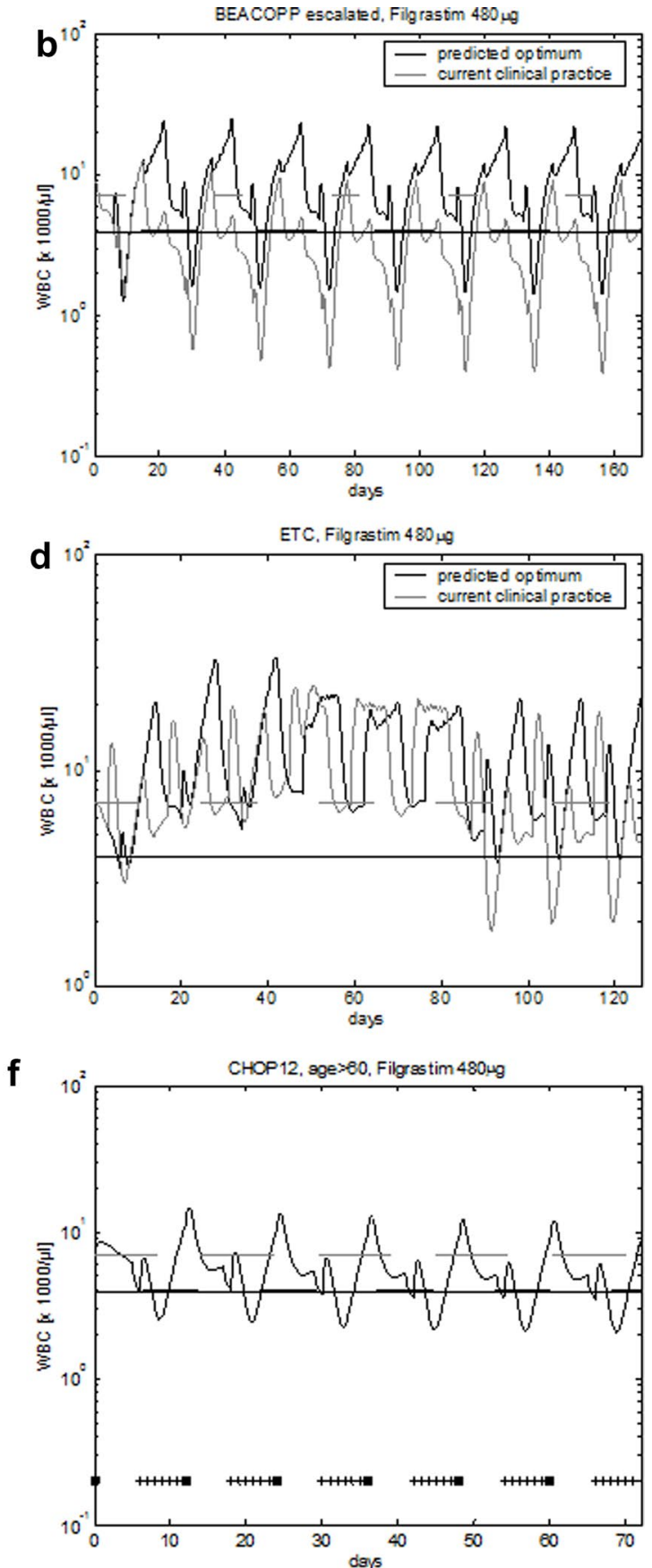

cycles results in a predicted optimal G-CSF treatment at days 7-14. e, f CHOP-12 (hypothetical chemotherapy of elderly patients): predicted optimal filgrastim treatment is $\mathrm{d} 7-12$. a, c, e The $X$-axis denotes the starting day of filgrastim. The $Y$-axis shows the number of filgrastim injections. The colour corresponds to the calculated WBCAOC (blue: lower WBCAOC, red: high WBCAOC). Background colour: WBCAOC obtained without G-CSF treatment

predict that the low-risk group can safely be treated with considerably less pegfilgrastim (Fig. S2e in Additional file 1). To a lesser extent, this also applies for the mediumand high-risk group if pegfilgrastim is administered within 

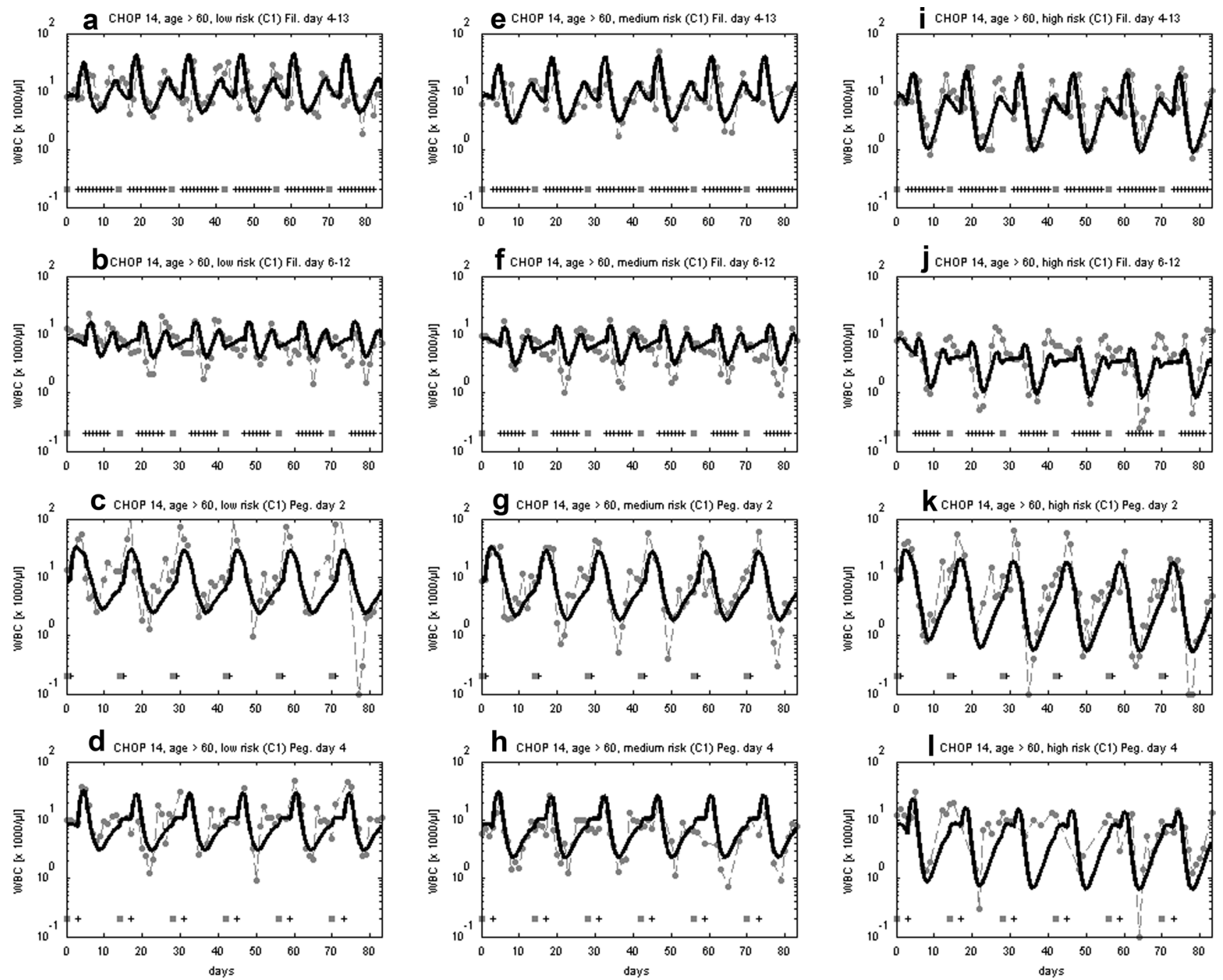

Fig. 6 Agreement of model and data for CHOP-14 considering three risk groups and four G-CSF schedules. We consider six cycles of CHOP-14 chemotherapy of non-Hodgkin's lymphoma for elderly patients (age $>60)$ at low leukopenic risk (a-d), medium leukopenic risk (e-h), and high leukopenic risk (i-l). Data and model prediction

the above-mentioned optimal time interval (Fig. S2a, c in Additional file 1).

\section{Discussion}

Although the haematopoietic growth factor G-CSF is routinely applied in clinical practice since many years, its optimal use in a given clinical situation is often unknown or not well investigated. The reason is that the performance of alternative G-CSF schedules is difficult to predict in view of the strong interaction of chemotherapy-induced leukopenia, pharmacokinetic properties of G-CSF and the resulting effects on bone marrow leukopoiesis. are compared for filgrastim on days $4-13$ or 6-12 and pegfilgrastim on day 2 or 4 . Dots represent patient medians, squares correspond to chemotherapy administrations, "+" corresponds to days with G-CSF injections

In view of the large number of variable therapy options (dosing and scheduling of cytotoxic drugs and G-CSF, different G-CSF pharmaceuticals, individual risk factors of patients), it is practically impossible to study this problem solely on the basis of clinical trials. Thus, there is a strong need for predictive modelling of G-CSF applications. Pastor et al. (2015) proposed a statistical model, while Quartino et al. (2014) proposed a semi-mechanistic model for this purpose. Craig et al. (2015) used their granulopoiesis model to explore alternative filgrastim schedules for general 14-day chemotherapy cycles. Here we propose to use our recently established biomathematical model of human granulopoiesis under G-CSF and chemotherapy treatments to address this task. Our model is based on biological assumptions on bone 
a
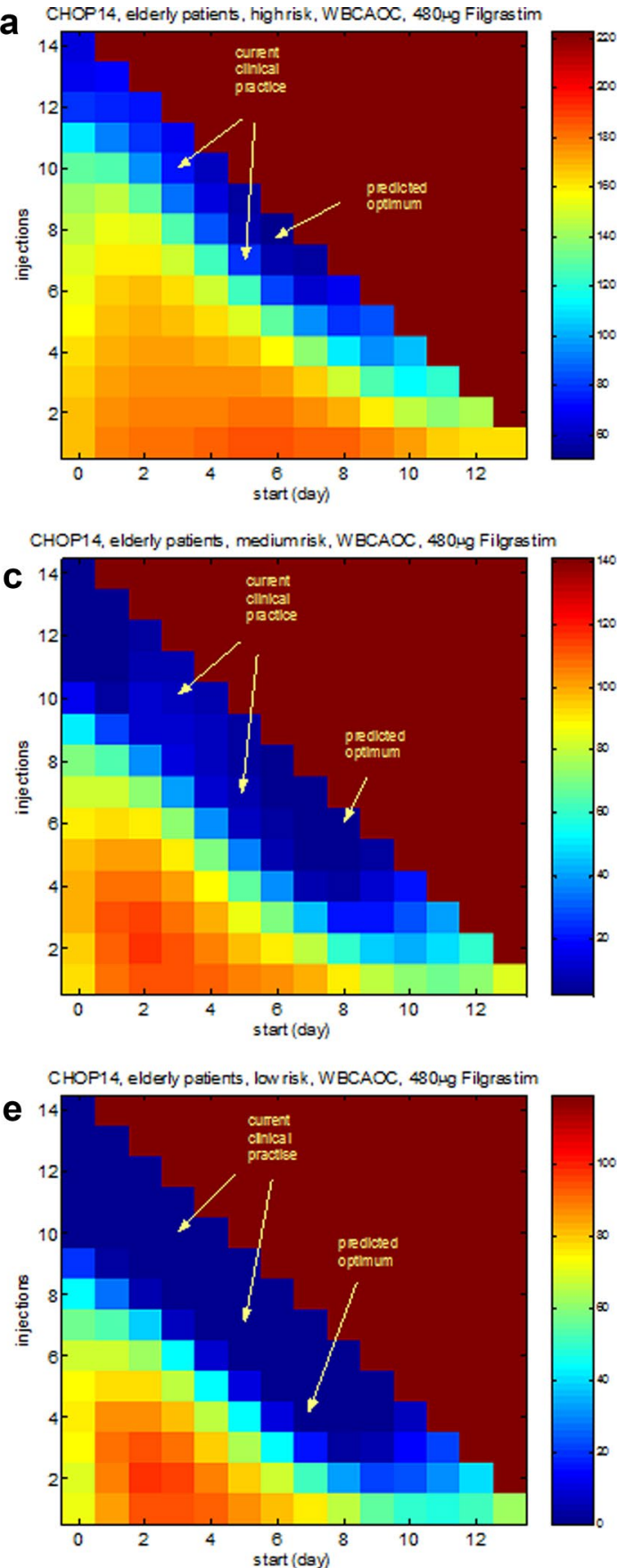

Fig. 7 Risk-specific G-CSF schedules for CHOP-14 chemotherapy of elderly patients. Optimization is performed for cycles 2-6 since first cycle toxicity is included into the risk model. a, b High-risk, c, d medium-risk, e, f low-risk group. a, c, e The colour corresponds to the predicted WBCAOC (blue: lower WBCAOC-lower toxicity,

marrow haematopoiesis, PK and PD effects of G-CSF injections and the cytotoxic effects of chemotherapy.

The model was developed on the basis of large clinical and literature data sets (Schirm et al. 2013, 2014a, b). To apply the model, it is necessary to estimate the
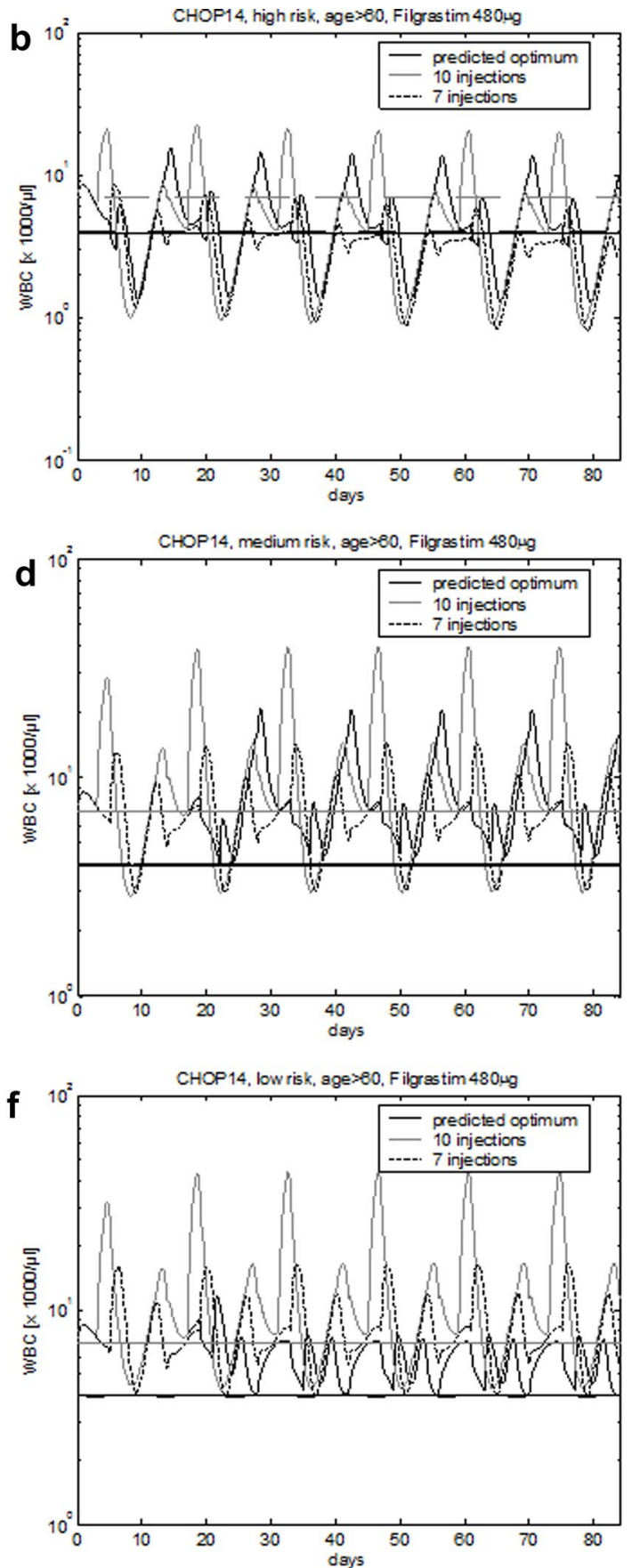

red: high WBCAOC-higher toxicity). The $X$-axis corresponds to the starting day of filgrastim treatment. The $Y$-axis represents the number of filgrastim injections. Background colour: toxicity obtained without G-CSF treatment. Panels $\mathbf{b}, \mathbf{d}$ and $\mathbf{f}$ show the WBC time course of the predicted optimal schedule in comparison to the current standard

bone marrow toxicity of an applied cytotoxic drug or drug combination, which can be achieved by studying timeseries data of patients treated under this condition. By this approach, we were able to quantify bone marrow toxicities of a total of 10 drugs and 33 schedules (Schirm et al. 
2014b). After quantifying the toxicity, the performance of alternative G-CSF schedules can be simulated by the model. We already applied this method in the planning phase of a number of clinical trials. Data collected under the newly proposed schedules showed that our predictions are in good agreement with the data. In view of these encouraging results, we propose additional optimized G-CSF schedules here. The proposed schedules are intended to be verified in clinical trials.

Different G-CSF derivatives are in practical use. Here we focused on filgrastim and pegfilgrastim which are generally considered as equally potent to prevent leukopenia if properly applied. A few studies and meta-analyses indicate advantages for pegfilgrastim (Clark et al. 2003, 2005; Cooper et al. 2011; Mhaskar et al. 2014; Lambertini et al. 2015). Indeed, pegfilgrastim can be applied more easily increasing compliance. But filgrastim can be dosed more precisely allowing individual adaptations. This is especially relevant for risk-adapted G-CSF treatments. Moreover, it is supposed that the amount of pegfilgrastim injected by a single standard syringe might be too high for some patients (Ishiguro et al. 2008; Djulbegovic et al. 2013; Masuda et al. 2015). Therefore, going beyond pure variation of starting time of pegfilgrastim, we also considered scenarios with reduced dosage of pegfilgrastim.

We studied different outcomes to assess the resulting cytotoxic outcome of a schedule, namely WBCAOC, DoL and MLC. Pros and cons of these outcomes are discussed elsewhere (Scholz et al. 2006) and we propose WBCAOC as the most reasonable choice. This allows us to compare different G-CSF schedules with respect to their expected cytotoxic outcome, and finally, to optimize the schedules. The relationship between the degree of chemotherapyinduced leukopenia and resulting risk for infections is well-established (Colotta et al. 1992; Bennett et al. 2013; Li et al. 2016).

As practical applications of our model, we considered for example different starting times of pegfilgrastim for the adjuvant breast cancer chemotherapy ETC in the patient population studied in Moebus et al. (2010). According to our simulations, we predict that the application at $\mathrm{d} 4$ after chemotherapy is superior to $\mathrm{d} 2$ and that $\mathrm{d} 6$ is optimal. However, the differences are small. Moreover, the strongest leukopenic risk is expected for the cycles with cyclophosphamide applications. Here, the nadir occurs in a narrow time interval which might be difficult to capture in a clinical trial. This could explain the results of Loibl et al. (2011) who observed a (non-significant) trend towards better performance of the $\mathrm{d} 4$ schedule compared to $\mathrm{d} 2$.

For the BEACOPP escalated regimen to treat advance stage Hodgkin's lymphoma (Diehl et al. 2003), we predict that pegfilgrastim is optimally applied at d6-7 after chemotherapy. However, this would still fall into the period of procarbacine treatment.

We also propose optimized filgrastim treatment for three scenarios: for BEACOPP escalated, we predict that starting 1 day earlier and increasing the number of G-CSF injections would result in improved leukopenia prophylaxis. For the ETC chemotherapy mentioned above, we predict that filgrastim d7-14 after chemotherapy is clearly superior to the current standard $\mathrm{d} 4-11$. But since the haematotoxic risk clearly depends on the applied drugs, we also considered different filgrastim schedules for cycles 1-3 (epirubicin), 4-6 (paclitaxel) and 7-9 (cyclophosphamide), respectively. However, only small improvements were predicted compared to the $\mathrm{d} 7-14$ schedule.

Since time-intensified CHOP is advantageous for the treatment of high-grade non-Hodgkin's lymphoma in elderly patients (Pfreundschuh et al. 2004a; Roesch et al. 2014; Rosch et al. 2016), we designed a regimen with six cycles of CHOP repeated every 12 days (CHOP-12). We predict that with optimal filgrastim support at $\mathrm{d} 7-12$, the toxicity might be tolerable but slightly cumulates over six cycles.

Another application of the model is the development of risk-adapted G-CSF schedules as recommended (Kuderer et al. 2006; Georgala and Klastersky 2015). This is achieved under the assumption that risk groups differ in sensitivity to chemotherapeutic drugs rather than response to G-CSF treatment (Chatta et al. 1994). We established a statistical model of leukopenia risk, depending on pre-therapeutical (i.e. age, sex) and intra-therapeutical (observed toxicity in first cycle) risk factors for patients of high-grade non-Hodgkin's lymphoma in the past (Ziepert et al. 2008). However, the risk score did not result in recommendations regarding individualized G-CSF regimen so far. We addressed this issue in our paper by dividing patients into tertiles for which we propose specific G-CSF schedules. Indeed, we could detect some potential for risk-dependent filgrastim treatment: For the optimal schedules, number of filgrastim injections differed between four for the low-risk group, six for the medium-risk group and eight for the high-risk group. No optimization potential was detected for single pegfilgrastim injections (optimum d6-7 after chemotherapy for all risk groups). This approach can be generalized to other therapy schedules for which a leukopenia risk score is available.

As a general recommendation observed throughout our scenarios, we conclude that filgrastim and pegfilgrastim treatment should not be started too early after chemotherapy. The major reason is that G-CSF releases the bone marrow reserve of granulocytes which should be avoided if the number of granulocytes is still sufficiently high. However, this might be applicable only for intense chemotherapies with a high risk of leukopenia (Whitworth et al. 2009; Cheng et al. 2014). Moreover, filgrastim should not be stopped too early. Even if granulocytes are recovered, we predict a 
benefit of maintained G-CSF treatment in the subsequent chemotherapy cycle. According to our model simulations, we also expect that there is some potential to reduce the dose of single pegfilgrastim injections without loss of efficacy. However, this prediction must be considered with caution since it is based on extrapolation of absorption kinetics.

A limitation of our method is that we only consider the number of leukocytes and not the clinically more relevant outcome of infection. Although there are strong relationships between leukocyte counts and risk for infection (Bennett et al. 2013; Colotta et al. 1992), our method does not account for leukocyte function or other measures to prevent infections such as prophylactic antibiotic treatment or hospitalization. Another limitation is that we optimized G-CSF therapy for the medians of patient populations or risk groups while patient extremes are most relevant. We aim at addressing this issue by modelling individual time courses in the future.

\section{Conclusions}

We conclude that we established a biomathematical model of human granulopoiesis under chemotherapy which allows predictions of yet untested G-CSF schedules, comparisons between them, and with it, optimization of filgrastim and pegfilgrastim treatment. Some model predictions were already validated in clinical trials. We provided a number of additional suggestions for optimized G-CSF schedules for chemotherapies of different diseases and risk groups. As a general rule of thumb, G-CSF treatment should not be started too early and patients could profit from filgrastim treatment continued until the end of the chemotherapy cycle.

Acknowledgements We thank the German Hodgkin's Lymphoma Study Group (Volker Diehl), the German High-Grade Non-Hodgkin's Lymphoma Study Group (Michael Pfreundschuh) and the German Breast Group (Gunther von Minckwitz, Sibylle Loibl) for kind permission to use clinical trial data. We acknowledge support from the German Research Foundation (DFG). This work was supported by the German Federal Ministry of Research and Education, Grant number 031A424 "HaematoOPT".

Author contributions Developed the model: SS, CE, MS. Conceived and designed model simulations: SS, MS. Performed model simulations: SS. Wrote the article: SS, MS. Contributed to discussion: CE, SL, ML. Final approval of manuscript: all authors.

\section{Compliance with ethical standards}

Ethics approval and consent to participate Data were obtained from studies of German Hodgkin's Lymphoma Study Group, German High-Grade Non-Hodgkin's Lymphoma Study Group, and German Breast Group. All patients had given informed consent and studies were approved by responsible ethics committees and were carried out in accordance with the principles of good clinical practice and the declaration of Helsinki. Details on ethics committees and reference numbers can be found in the respective publications of the studies used for our modelling: (Moebus et al. 2010; Pfreundschuh et al. 2008, 2004a; Trumper et al. 2008; Zwick et al. 2011).

Funding This work was supported by the German Federal Ministry of Research and Education, Grant number 031A424 "HaematoOPT".

Consent for publication Not applicable.

Availability of data and material All relevant data to support our modelling are presented in the paper and the supplement material.

Conflict of interest Markus Scholz declared a commercial relationship with Merck Serono with respect to consulting, data analysis and modelling. The other authors declared no conflicts of interest.

Open Access This article is distributed under the terms of the Creative Commons Attribution 4.0 International License (http://creativecommons.org/licenses/by/4.0/), which permits unrestricted use, distribution, and reproduction in any medium, provided you give appropriate credit to the original author(s) and the source, provide a link to the Creative Commons license, and indicate if changes were made.

\section{References}

Altwairgi AK, Hopman WM, Mates M (2013) Real-world impact of granulocyte-colony stimulating factor on febrile neutropenia. Curr Oncol 20(3):9. https://doi.org/10.3747/co.20.1306

Bennett CL, Sinkule JA, Schilsky RL, Senekjian E, Choi KE (1987) Phase I clinical and pharmacological study of 72-hour continuous infusion of etoposide in patients with advanced cancer. Cancer Res 47(7):1952-1956

Bennett CL, Djulbegovic B, Norris LB, Armitage JO (2013) Colonystimulating factors for febrile neutropenia during cancer therapy. N Engl J Med 368(12):1131-1139. https://doi.org/10.1056/ NEJMct1210890

Blayney DW, LeBlanc ML, Grogan T, Gaynor ER, Chapman RA, Spiridonidis CH, Taylor SA, Bearman SI, Miller TP, Fisher RI (2003) Dose-intense chemotherapy every 2 weeks with dose-intense cyclophosphamide, doxorubicin, vincristine, and prednisone may improve survival in intermediate- and high-grade lymphoma: A phase II study of the Southwest Oncology Group (SWOG 9349). J Clin Oncol 21(13):2466-2473. https://doi.org/10.1200/ Jco.2003.06.137

Blayney DW, McGuire BW, Cruickshank SE, Johnson DH (2005) Increasing chemotherapy dose density and intensity: phase I trials in non-small cell lung cancer and non-Hodgkin's lymphoma. Oncologist 10(2):138-149. https://doi.org/10.1634/ theoncologist.10-2-138

Bohlius J, Herbst C, Reiser M, Schwarzer G, Engert A (2008) Granulopoiesis-stimulating factors to prevent adverse effects in the treatment of malignant lymphoma. Cochrane Database Syst Rev (4):CD003189. 10.1002/14651858.CD003189.pub4

Bruno R, Riva A, Hille D, Lebecq A, Thomas L (1997) Pharmacokinetic and pharmacodynamic properties of docetaxel: results of phase I and phase II trials. Am J Health Syst Pharm Off J Am Soc Health Syst Pharm 54(24 Suppl 2):9

Chatta GS, Price TH, Allen RC, Dale DC (1994) Effects of in vivo recombinant methionyl human granulocyte colony-stimulating factor on the neutrophil response and peripheral blood colonyforming cells in healthy young and elderly adult volunteers. Blood 84(9):2923-2929 
Cheng C, Gallagher EM, Yeh J-Y, Earl MA (2014) Rates of febrile neutropenia with pegfilgrastim on same day versus next day of CHOP with or without rituximab. Anticancer Drugs 25(8):964969. https://doi.org/10.1097/CAD.0000000000000115

Chua HL, Plett PA, Sampson CH, Katz BP, Carnathan GW, MacVittie TJ, Lenden K, Orschell CM (2014) Survival efficacy of the PEGylated G-CSFs Maxy-G34 and neulasta in a mouse model of lethal H-ARS, and residual bone marrow damage in treated survivors. Health Phys 106(1):21-38. https://doi.org/10.1097/ HP.0b013e3182a4df10

Clark OAC, Lyman G, Castro AA, Clark LGO, Djulbegovic B (2003) Colony stimulating factors for chemotherapy induced febrile neutropenia. Cochrane Database Syst Rev (3):CD003039. 10.1002/14651858.CD003039

Clark OAC, Lyman GH, Castro AA, Clark LGO, Djulbegovic B (2005) Colony-stimulating factors for chemotherapy-induced febrile neutropenia: a meta-analysis of randomized controlled trials. J Clin Oncol 23(18):4198-4214. https://doi.org/10.1200/ JCO.2005.05.645

Colotta F, Re F, Polentarutti N, Sozzani S, Mantovani A (1992) Modulation of granulocyte survival and programmed cell-death by cytokines and bacterial products. Blood 80(8):2012-2020

Cooper KL, Madan J, Whyte S, Stevenson MD, Akehurst RL (2011) Granulocyte colony-stimulating factors for febrile neutropenia prophylaxis following chemotherapy: systematic review and meta-analysis. BMC Cancer 11:404. https://doi. org/10.1186/1471-2407-11-404

Craig M, Humphries AR, Nekka F, Belair J, Li J, Mackey MC (2015) Neutrophil dynamics during concurrent chemotherapy and G-CSF administration: mathematical modelling guides dose optimisation to minimise neutropenia. J Theor Biol 385:77-89. https://doi. org/10.1016/j.jtbi.2015.08.015

Crawford J, Ozer H, Stoller R, Johnson D, Lyman G, Tabbara I, Kris M, Grous J, Picozzi V, Rausch G (1991) Reduction by granulocyte colony-stimulating factor of fever and neutropenia induced by chemotherapy in patients with small-cell lung cancer. N Engl J Med 325(3):164-170. https://doi.org/10.1056/ NEJM199107183250305

Crawford J, Kreisman H, Garewal H, Jones SE, Shoemaker D, Pupa MR, Armstrong S, Tomita D, Dziem G (1997) The impact of Filgrastim schedule variation on hematopoietic recovery postchemotherapy. Ann Oncol 8(11):1117-1124

Crawford J, Dale DC, Lyman GH (2004) Chemotherapy-induced neutropenia: risks, consequences, and new directions for its management. Cancer 100(2):228-237. https://doi.org/10.1002/cncr.11882

Dale DC (2002) Colony-stimulating factors for the management of neutropenia in cancer patients. Drugs 62(Suppl 1):1-15

Dale D (2003) Current management of chemotherapy-induced neutropenia: the role of colony-stimulating factors. Semin Oncol 30(4 Suppl 13):3-9

Danova M, Chiroli S, Rosti G, Doan QV (2009) Cost-effectiveness of pegfilgrastim versus six days of filgrastim for preventing febrile neutropenia in breast cancer patients. Tumori 95(2):219-226

Diehl V, Franklin J, Pfreundschuh M, Lathan B, Paulus U, Hasenclever D, Tesch H, Herrmann R, Dorken B, Muller-Hermelink H, Duhmke E, Loeffler M, German Hodgkin's Lymphoma Study Group [Nachname nicht vorhanden] (2003) Standard and increaseddose BEACOPP chemotherapy compared with COPP-ABVD for advanced Hodgkin's disease. N Engl J Med 348(24):2386-2395. https://doi.org/10.1056/Nejmoa022473

Djulbegovic B, Norris LB, Bennett CL (2013) Colony-stimulating factors for febrile neutropenia. N Engl J Med 369(3):286. https://doi. org/10.1056/NEJMc1306109

Engel C, Scholz M, Loeffler M (2004) A computational model of human granulopoiesis to simulate the hematotoxic effects of multicycle polychemotherapy. Blood 104(8):2323-2331. https:// doi.org/10.1182/blood-2004-01-0306

Faber E, Pytlik R, Slaby J, Zapletalova J, Kozak T, Raida L, Papajik T, Zikesova E, Maresova I, Hamouzova M, Indrak K, Trneny M (2006) Individually determined dosing of filgrastim after autologous peripheral stem cell transplantation in patients with malignant lymphoma-results of a prospective multicentre controlled trial. Eur J Haematol 77(6):493-500. https://doi. org/10.1111/j.1600-0609.2006.00741.x

Georgala A, Klastersky JA (2015) Prophylaxis of febrile neutropenia in adults receiving chemotherapy needs to be adapted to the risk. Expert Rev Hematol 8(1):115-121. https://doi.org/10.1586/1747 4086.2015.983470

Gross A, Schirm S, Scholz M (2014) Ycasd—a tool for capturing and scaling data from graphical representations. BMC Bioinform 15(219):219. https://doi.org/10.1186/1471-2105-15-219

Harris JM, Chess RB (2003) Effect of pegylation on pharmaceuticals. Nat Rev Drug Discov 2(3):214-221. https://doi.org/10.1038/ nrd1033

Holmes FA, Jones SE, O'Shaughnessy J, Vukelja S, George T, Savin M, Richards D, Glaspy J, Meza L, Cohen G, Dhami M, Budman DR, Hackett J, Brassard M, Yang BB, Liang BC (2002) Comparable efficacy and safety profiles of once-per-cycle pegfilgrastim and daily injection filgrastim in chemotherapy-induced neutropenia: a multicenter dose-finding study in women with breast cancer. Ann Oncol Off J Eur Soc Med Oncol 13(6):903-909

Houston AC, Stevens LA, Cour V (1999) Pharmacokinetics of glycosylated recombinant human granulocyte colony-stimulating factor (lenograstim) in healthy male volunteers. Brit J Clin Pharmacol 47(3):279-284

Ishiguro H, Kitano T, Yoshibayashi H, Toi M, Ueno T, Yasuda H, Yanagihara K, Garbo CL, Fukushima M (2008) Prolonged neutropenia after dose-dense chemotherapy with pegfilgrastim. Ann Oncol 19(5):1019. https://doi.org/10.1093/annonc/mdn051 (author reply 1019-20)

Iyer L, Ratain MJ (1999) 5-Fluorouracil pharmacokinetics: causes for variability and strategies for modulation in cancer chemotherapy. Cancer Investig 17(7):494-506

Kloft C, Wallin J, Henningsson A, Chatelut E, Karlsson MO (2006) Population pharmacokinetic-pharmacodynamic model for neutropenia with patient subgroup identification: comparison across anticancer drugs. Clin Cancer Res Off J Am Assoc Cancer Res 12(18):5481-5490. https://doi.org/10.1158/1078-0432. CCR-06-0815

Kosaka Y, Rai Y, Masuda N, Takano T, Saeki T, Nakamura S, Shimazaki R, Ito Y, Tokuda Y, Tamura K (2015) Phase III placebo-controlled, double-blind, randomized trial of pegfilgrastim to reduce the risk of febrile neutropenia in breast cancer patients receiving docetaxel/cyclophosphamide chemotherapy. Support Care Cancer 23(4):1137-1143. https://doi.org/10.1007/ s00520-014-2597-1

Kota J, Machavaram KK, McLennan DN, Edwards GA, Porter CJ, Charman SA (2007) Lymphatic absorption of subcutaneously administered proteins: influence of different injection sites on the absorption of darbepoetin alfa using a sheep model. Drug Metab Dispos 35:2211-2217

Kuderer NM, Dale DC, Crawford J, Cosler LE, Lyman GH (2006) Mortality, morbidity, and cost associated with febrile neutropenia in adult cancer patients. Cancer 106(10):2258-2266. https://doi. org/10.1002/cncr.21847

Kuderer NM, Dale DC, Crawford J, Lyman GH (2007) Impact of primary prophylaxis with granulocyte colony-stimulating factor on febrile neutropenia and mortality in adult cancer patients receiving chemotherapy: a systematic review. J Clin Oncol 25(21):31583167. https://doi.org/10.1200/Jco.2006.08.8823 
Kuwabara T, Kato Y, Kobayashi S, Suzuki H, Sugiyama Y (1994) Nonlinear pharmacokinetics of a recombinant human granulocyte-colony-stimulating factor derivative (nartograstim) — speciesdifferences among rats, monkeys and humans. J Pharmacol Exp Ther 271(3):1535-1543

Kuwabara T, Kobayashi S, Sugiyama Y (1996a) Kinetic analysis of receptor-mediated endocytosis of G-CSF derivative, nartograstim, in rat bone marrow cells. Am J Physiol 271(1 Pt 1):84

Kuwabara T, Kobayashi S, Sugiyama Y (1996b) Pharmacokinetics and pharmacodynamics of a recombinant human granulocyte colonystimulating factor. Drug Metab Rev 28(4):625-658. https://doi. org/10.3109/03602539608994020

Lambertini M, Ferreira AR, Del Mastro L, Danesi R, Pronzato P (2015) Pegfilgrastim for the prevention of chemotherapy-induced febrile neutropenia in patients with solid tumors. Expert Opin Biol Ther 15(12):1799-1817. https://doi.org/10.1517/14712598.2015.110 1063

Lee S, Knox A, Zeng ISL, Coomarasamy C, Blacklock H, Issa S (2013) Primary prophylaxis with granulocyte colony-stimulating factor (GCSF) reduces the incidence of febrile neutropenia in patients with non-Hodgkin lymphoma (NHL) receiving CHOP chemotherapy treatment without adversely affecting their quality of life: cost-benefit and quality of life analysis. Support Care Cancer 21(3):841-846. https://doi.org/10.1007/s00520-012-1589-2

Leonard RCF, Mansi JL, Keerie C, Yellowlees A, Crawford S, Benstead K, Matthew R, Adamson D, Chan S, Grieve R (2015) A randomised trial of secondary prophylaxis using granulocyte colony-stimulating factor ('SPROG' trial) for maintaining dose intensity of standard adjuvant chemotherapy for breast cancer by the Anglo-Celtic Cooperative Group and NCRN. Ann Oncol 26(12):2437-2441. https://doi.org/10.1093/annonc/mdv389

Li Y, Klippel Z, Shih X, Reiner M, Wang H, Page JH (2016) Relationship between severity and duration of chemotherapy-induced neutropenia and risk of infection among patients with nonmyeloid malignancies. Support Care Cancer. https://doi.org/10.1007/ s00520-016-3277-0

Loibl S, Mueller V, von Minckwitz G, Conrad B, Koehne C-H, Kremers S, Forstbauer H, Linder M, Nekljudova V, Moebus V (2011) Comparison of pegfilgrastim on day 2 vs. day 4 as primary prophylaxis of intense dose-dense chemotherapy in patients with nodepositive primary breast cancer within the prospective, multi-center GAIN study: (GBG 33). Support Care Cancer 19(11):1789-1795. https://doi.org/10.1007/s00520-010-1020-9

Lord BI, Bronchud MH, Owens S, Chang J, Howell A, Souza L, Dexter TM (1989) The kinetics of human granulopoiesis following treatment with granulocyte colony-stimulating factor in vivo. Proc Natl Acad Sci USA 86(23):9499-9503

Lyman G, Lalla A, Barron R, Dubois RW (2009) Cost-effectiveness of pegfilgrastim versus 6-day filgrastim primary prophylaxis in patients with non-Hodgkin's lymphoma receiving CHOP-21 in United States. Curr Med Res Opin 25(2):401-411. https://doi. org/10.1185/03007990802636817

Mackey MC, Aprikyan AA, Dale DC (2003) The rate of apoptosis in post mitotic neutrophil precursors of normal and neutropenic humans. Cell Prolif 36(1):27-34

Masuda N, Tokuda Y, Nakamura S, Shimazaki R, Ito Y, Tamura K (2015) Dose response of pegfilgrastim in Japanese breast cancer patients receiving six cycles of docetaxel, doxorubicin, and cyclophosphamide therapy: a randomized controlled trial. Support Care Cancer 23(10):2891-2898. https://doi.org/10.1007/ s00520-015-2654-4

Mhaskar R, Clark OAC, Lyman G, Engel Ayer Botrel T, Morganti Paladini L, Djulbegovic B (2014) Colony-stimulating factors for chemotherapy-induced febrile neutropenia. Cochrane Database Syst Rev (10):CD003039. 10.1002/14651858.CD003039.pub2
Moebus V, Jackisch C, Lueck H-J, Du Bois A, Thomssen C, Kurbacher C, Kuhn W, Nitz U, Schneeweiss A, Huober J, Harbeck N, von Minckwitz G, Runnebaum IB, Hinke A, Kreienberg R, Konecny GE, Untch M (2010) Intense dose-dense sequential chemotherapy with epirubicin, paclitaxel, and cyclophosphamide compared with conventionally scheduled chemotherapy in highrisk primary breast cancer: mature results of an AGO phase III study. J Clin Oncol 28(17):2874-2880. https://doi.org/10.1200/ JCO.2009.24.7643

Molineux G (2002) Pegylation: engineering improved pharmaceuticals for enhanced therapy. Cancer Treat Rev 28(Suppl A):13-16

Pastor ML, Laffont CM, Gladieff L, Chatelut E, Concordet D (2015) Model-based approach to early predict prolonged high grade neutropenia in carboplatin-treated patients and guide G-CSF prophylactic treatment. Pharm Res 32(2):654-664. https://doi. org/10.1007/s11095-014-1493-1

Pettengell R, Gurney H, Radford JA, Deakin DP, James R, Wilkinson PM, Kane K, Bentley J, Crowther D (1992) Granulocyte colony-stimulating factor to prevent dose-limiting neutropenia in non-Hodgkin's lymphoma: a randomized controlled trial. Blood 80(6):1430-1436

Pfreundschuh M, Trumper L, Kloess M, Schmits R, Feller AC, Rube C, Rudolph C, Reiser M, Hossfeld DK, Eimermacher H, Hasenclever D, Schmitz N, Loeffler M (2004a) Two-weekly or 3-weekly CHOP chemotherapy with or without etoposide for the treatment of elderly patients with aggressive lymphomas: results of the NHL-B2 trial of the DSHNHL. Blood 104(3):634-641. https://doi.org/10.1182/blood-2003-06-2095

Pfreundschuh M, Trumper L, Kloess M, Schmits R, Feller AC, Rudolph C, Reiser M, Hossfeld DK, Metzner B, Hasenclever D, Schmitz N, Glass B, Rube C, Loeffler M (2004b) Two-weekly or 3-weekly CHOP chemotherapy with or without etoposide for the treatment of young patients with good-prognosis (normal LDH) aggressive lymphomas: results of the NHL-B1 trial of the DSHNHL. Blood 104(3):626-633. https://doi.org/10.1182/ blood-2003-06-2094

Pfreundschuh M, Schubert J, Ziepert M, Schmits R, Mohren M, Lengfelder E, Reiser M, Nickenig C, Clemens M, Peter N, Bokemeyer C, Eimermacher H, Ho A, Hoffmann M, Mertelsmann R, Trumper L, Balleisen L, Liersch R, Metzner B, Hartmann F, Glass B, Poeschel V, Schmitz N, Ruebe C, Feller AC, Loeffler M, German High-Grade Non-Hodgkin Lymphoma Study Group (2008) Six versus eight cycles of bi-weekly CHOP-14 with or without rituximab in elderly patients with aggressive CD20 + B-cell lymphomas: a randomised controlled trial (RICOVER-60). Lancet Oncol 9(2):105-116. https://doi.org/10.1016/S1470-2045(08)70002-0

Quartino AL, Karlsson MO, Lindman H, Friberg LE (2014) Characterization of endogenous G-CSF and the inverse correlation to chemotherapy-induced neutropenia in patients with breast cancer using population modeling. Pharm Res 31(12):3390-3403. https:// doi.org/10.1007/s11095-014-1429-9

Rechenberg I (1973) Evolutionsstrategie. Optimierung technischer Systeme nach Prinzipien der biologischen Evolution. FrommannHolzboog, Stuttgart

Rechenberg I (1994) Evolutionsstrategie 94. Frommann-Holzboog, Stuttgart

Roesch K, Hasenclever D, Scholz M (2014) Modelling lymphoma therapy and outcome. Bull Math Biol 76(2):401-430. https://doi. org/10.1007/s11538-013-9925-3

Rosch K, Scholz M, Hasenclever D (2016) Modeling combined chemoand immunotherapy of high-grade non-Hodgkin lymphoma. Leuk Lymphoma 57(7):1697-1708. https://doi.org/10.3109/10428194. 2015.1110746

Rushing DA, Raber SR, Rodvold KA, Piscitelli SC, Plank GS, Tewksbury DA (1994) The effects of cyclosporine on the 
pharmacokinetics of doxorubicin in patients with small cell lung cancer. Cancer 74(3):834-841

Sarkar CA, Lowenhaupt K, Wang PJ, Horan T, Lauffenburger DA (2003) Parsing the effects of binding, signaling, and trafficking on the mitogenic potencies of granulocyte colony-stimulating factor analogues. Biotechnol Prog 19(3):955-964. https://doi. org/10.1021/bp020017g

Schirm S, Engel C, Loeffler M, Scholz M (2013) A biomathematical model of human erythropoiesis under erythropoietin and chemotherapy administration. PLoS One 8(6):e65630. https:// doi.org/10.1371/journal.pone.0065630

Schirm S, Engel C, Loeffler M, Scholz M (2014a) A combined model of human erythropoiesis and granulopoiesis under growth factor and chemotherapy treatment. Theor Biol Med Model 11:24. https://doi. org/10.1186/1742-4682-11-24

Schirm S, Engel C, Loeffler M, Scholz M (2014b) Modelling chemotherapy effects on granulopoiesis. BMC Syst Biol 8(1):5. https:// doi.org/10.1186/s12918-014-0138-7

Schmitz S, Franke H, Brusis J, Wichmann HE (1993) Quantification of the cell kinetic effects of G-CSF using a model of human granulopoiesis. Exp Hematol 21(6):755-760

Scholz M, Engel C, Loeffler M (2005) Modelling human granulopoiesis under poly-chemotherapy with G-CSF support. J Math Biol 50(4):397-439. https://doi.org/10.1007/s00285-004-0295-1

Scholz M, Engel C, Loeffler M, German High Grade Non-Hodgkin Lymphoma Study Group (2006) Model-based design of chemotherapeutic regimens that account for heterogeneity in leucopoenia. Br J Haematol 132(6):723-735. https://doi. org/10.1111/j.1365-2141.2005.05957.x

Scholz M, Ackermann M, Engel C, Emmrich F, Loeffler M, Kamprad M (2009a) A pharmacokinetic model of filgrastim and pegfilgrastim application in normal mice and those with cyclophosphamideinduced granulocytopaenia. Cell Prolif 42(6):813-822. https://doi. org/10.1111/j.1365-2184.2009.00638.x

Scholz M, Engel C, Apt D, Sankar SL, Goldstein E, Loeffler M (2009b) Pharmacokinetic and pharmacodynamic modelling of the novel human granulocyte colony-stimulating factor derivative MaxyG34 and pegfilgrastim in rats. Cell Prolif 42(6):823-837. https:// doi.org/10.1111/j.1365-2184.2009.00641.x

Scholz M, Schirm S, Wetzler M, Engel C, Loeffler M (2012) Pharmacokinetic and -dynamic modelling of G-CSF derivatives in humans. Theor Biol Med Model 9:32. https://doi. org/10.1186/1742-4682-9-32

Sieber M, Bredenfeld H, Josting A, Reineke T, Rueffer U, Koch T, Naumann R, Boissevain F, Koch P, Worst P, Soekler M, Eich H, MullerHermelink HK, Franklin J, Paulus U, Wolf J, Engert A, Diehl V (2003) 14-Day variant of the bleomycin, etoposide, doxorubicin, cyclophosphamide, vincristine, procarbazine, and prednisone regimen in advanced-stage Hodgkin's lymphoma: results of a pilot study of the German Hodgkin's Lymphoma Study Group. J Clin Oncol 21(9):1734-1739. https://doi.org/10.1200/Jco.2003.06.028

Sulkes A, Collins JM (1987) Reappraisal of some dosage adjustment guidelines. Cancer Treat Rep 71(3):229-233

Sung L, Nathan PC, Alibhai SMH, Tomlinson GA, Beyene J (2007) Meta-analysis: effect of prophylactic hematopoietic colony-stimulating factors on mortality and outcomes of infection. Ann Intern Med 147(6):400-411

Trumper L, Zwick C, Ziepert M, Hohloch K, Schmits R, Mohren M, Liersch R, Bentz M, Graeven U, Wruck U, Hoffmann M, Metzner B, Hasenclever D, Loeffler M, Pfreundschuh M, German High-Grade Non-Hodgkin's Lymphoma Study Group (2008) Dose-escalated CHOEP for the treatment of young patients with aggressive nonHodgkin's lymphoma: I. A randomized dose escalation and feasibility study with bi- and tri-weekly regimens. Ann Oncol Off J Eur Soc Med Oncol 19(3):538-544. https://doi.org/10.1093/annonc/mdm497
Untch M, Fasching PA, Konecny GE, von Koch F, Conrad U, Fett W, Kurzeder C, Luck HJ, Stickeler E, Urbaczyk H, Liedtke B, Salat C, Harbeck N, Muller V, Schmidt M, Hasmuller S, Lenhard M, Schuster T, Nekljudova V, Lebeau A, Loibl S, von Minckwitz G, Arbeitsgemeinschaft Gynakologische Onkologie Prepare Investigators (2011a) PREPARE trial: a randomized phase III trial comparing preoperative, dose-dense, dose-intensified chemotherapy with epirubicin, paclitaxel and CMF versus a standard-dosed epirubicin/ cyclophosphamide followed by paclitaxel \pm darbepoetin alfa in primary breast cancer-results at the time of surgery. Ann Oncol Off J Eur Soc Med Oncol 22(9):1988-1998. https://doi.org/10.1093/ annonc/mdq709

Untch M, von Minckwitz G, Konecny GE, Conrad U, Fett W, Kurzeder C, Luck HJ, Stickeler E, Urbaczyk H, Liedtke B, Beckmann MW, Salat C, Harbeck N, Muller V, Schmidt M, Hasmuller S, Lenhard M, Nekljudova V, Lebeau A, Loibl S, Fasching PA, Arbeitsgemeinschaft Gynakologische Onkologie Prepare Investigators (2011b) PREPARE trial: a randomized phase III trial comparing preoperative, dose-dense, dose-intensified chemotherapy with epirubicin, paclitaxel, and CMF versus a standard-dosed epirubicin-cyclophosphamide followed by paclitaxel with or without darbepoetin alfa in primary breast cancer-outcome on prognosis. Ann Oncol Off J Eur Soc Med Oncol 22(9):1999-2006. https://doi.org/10.1093/ annonc/mdq713

Veronese FM, Mero A (2008) The impact of PEGylation on biological therapies. BioDrugs Clin Immunother Biopharm Gene Ther 22(5):315-329

Vogel CL, Wojtukiewicz MZ, Carroll RR, Tjulandin SA, BarajasFigueroa LJ, Wiens BL, Neumann TA, Schwartzberg LS (2005) First and subsequent cycle use of pegfilgrastim prevents febrile neutropenia in patients with breast cancer: a multicenter, double-blind, placebo-controlled phase III study. J Clin Oncol 23(6):1178-1184. https://doi.org/10.1200/JCO.2005.09.102

Vose JM, Crump M, Lazarus H, Emmanouilides C, Schenkein D, Moore J, Frankel S, Flinn I, Lovelace W, Hackett J, Liang BC (2003) Randomized, multicenter, open-label study of pegfilgrastim compared with daily filgrastim after chemotherapy for lymphoma. J Clin Oncol Off J Am Soc Clin Oncol 21(3):514-519

Wang XJ, Tang T, Farid M, Quek R, Tao M, Lim ST, Wee HL, Chan A (2016) Routine primary prophylaxis for febrile neutropenia with biosimilar granulocyte colony-stimulating factor (nivestim) or pegfilgrastim is cost effective in non-hodgkin lymphoma patients undergoing curative-intent R-CHOP chemotherapy. PLoS One 11(2):e0148901. https://doi.org/10.1371/journal.pone.0148901

Whitworth JM, Matthews KS, Shipman KA, Numnum TM, Kendrick JE, Kilgore LC, Straughn JM Jr (2009) The safety and efficacy of day 1 versus day 2 administration of pegfilgrastim in patients receiving myelosuppressive chemotherapy for gynecologic malignancies. Gynecol Oncol 112(3):601-604. https://doi.org/10.1016/j. ygyno.2008.10.025

Yang BB, Lum PK, Hayashi MM, Roskos LK (2004) Polyethylene glycol modification of filgrastim results in decreased renal clearance of the protein in rats. J Pharm Sci 93(5):1367-1373. https://doi. org/10.1002/Jps.20024

Zagonel V, Babare R, Merola MC, Talamini R, Lazzarini R, Tirelli U, Carbone A, Monfardini S (1994) Cost-benefit of granulocyte colony-stimulating factor administration in older patients with nonHodgkin's lymphoma treated with combination chemotherapy. Ann Oncol 5(Suppl 2):127-132

Zamboni WC (2003) Pharmacokinetics of pegfilgrastim. Pharmacotherapy 23(8 Pt 2):9-14

Zeynalova S, Ziepert M, Scholz M, Schirm S, Zwick C, Pfreundschuh M, Loeffler M, German High-Grade Non-Hodgkin Lymphoma Study Group (2013) Comparison and modelling of pegylated or unpegylated G-CSF schedules in CHOP-14 regimen of elderly patients 
with aggressive B-cell lymphoma. Ann Hematol 92(12):1641-1652. https://doi.org/10.1007/s00277-013-1842-x

Ziepert M, Schmits R, Trumper L, Pfreundschuh M, Loeffler M, German High-Grade Non-Hodgkin's Lymphoma Study Group (2008) Prognostic factors for hematotoxicity of chemotherapy in aggressive non-Hodgkin's lymphoma. Ann Oncol Off J Eur Soc Med Oncol 19(4):752-762. https://doi.org/10.1093/annonc/mdm541
Zwick C, Hartmann F, Zeynalova S, Poschel V, Nickenig C, Reiser M, Lengfelder E, Peter N, Schlimok G, Schubert J, Schmitz N, Loeffler M, Pfreundschuh M, German High-Grade Non-Hodgkin Lymphoma Study Group (2011) Randomized comparison of pegfilgrastim day 4 versus day 2 for the prevention of chemotherapy-induced leukocytopenia. Ann Oncol Off J Eur Soc Med Oncol 22(8):1872-1877. https://doi.org/10.1093/annonc/mdq674 